\title{
Neuroprotective properties of ciliary neurotrophic factor on retinoic acid (RA)-predifferentiated SH-SY5Y neuroblastoma cells
}

\author{
Ke Wang ${ }^{1}$, Fanfan Zhou ${ }^{2}$, Xue Zhu ${ }^{1}$, Kai Zhang ${ }^{1}$, Biao Huang ${ }^{1}$, Lan Zhu ${ }^{1}$, Ling Zhu ${ }^{3}$ \\ ${ }^{1}$ Key Laboratory of Nuclear Medicine, Ministry of Health, Jiangsu Key Laboratory of Molecular Nuclear Medicine, Jiangsu Institute \\ of Nuclear Medicine, Wuxi, Jiangsu Province, China, ${ }^{2}$ The Faculty of Pharmacy, University of Sydney, New South Wales, Australia, \\ ${ }^{3}$ Save Sight Institute, University of Sydney, New South Wales, Australia
}

\begin{abstract}
Ciliary neurotrophic factor (CNTF) is a neurocytokine, which could promote survival and/or differentiation in many cell types. In this study, the biological effects of CNTF on retinoic acid (RA)-predifferentiated SH-SY5Y neuroblastoma cells and the underlying molecular mechanism of this effect were investigated for the first time. The results showed that RA was able to increase cells susceptibility to CNTF via regulating the expression levels of CNTF receptors. A further study revealed that CNTF could induce phosphorylation of STAT3, Akt and ERK1/2 in RA-predifferentiated SH-SY5Y neuroblastoma cells, while the promoting activity of CNTF on survival and neurite growth of cells was attenuated by co-treatment with JAK2 inhibitor AG490 (25 $\mu \mathrm{M})$, STAT3 inhibitor Curcumin ( $50 \mu \mathrm{M})$, PI3K inhibitor LY-294002 (50 $\mu \mathrm{M})$, but not by co-treatment with MEK inhibitor PD98059 $(50 \mu \mathrm{M})$. These findings suggested that JAK2/STAT3, as well as PI3K/AKt, play important roles in mediating the survival and neurite growth response of RA-predifferentiated cells to CNTF. Our study may be useful to further understand the functional role of CNTF and offer a convenient model to explore the therapeutic potential of CNTF in neurodegenerative diseases.
\end{abstract}

Key words: CNTF, SH-SY5Y neuroblastoma cells, survival, neurite outgrowth, signalling pathway.

\section{Introduction}

Neurotrophic factors such as the ciliary neurotrophic factor (CNTF) are essential proteins for the maintenance and survival of neurons in both developing and mature nervous systems [14,16,21]. In particular, CNTF is responsible for neurotransmitter synthesis and neurite outgrowth in certain neuronal populations [22,26]. CNTF is a $25-\mathrm{kDa}$ polypeptide that was originally isolated as a target-derived survival factor of parasympathetic ciliary ganglion neu- rons [19]. It is believed that CNTF's physiological role only becomes apparent after tissue injury due to its lack of hydrophobic sequence. Known cell-surface receptors for CNTF include CNTF receptor $\alpha$ (CNTFR $\alpha$ ), gp130, and LIF receptor (LIFR) [3,4]. Binding of CNTF to CNTFR $\alpha$ triggers heterodimerization of gp130 and LIFR, forming an active trimeric receptor complex and activates the downstream signalling pathway [25]. It has been established that JAK2/STAT3 pathway is mainly involved in survival of neurons in

Communicating author:

Ling Zhu, Save Sight Institute, University of Sydney, New South Wales, Australia, phone: +86 13814247452 ,

e-mail: ling.zhu@sydney.edu.au 
response to CNTF $[11,12,26]$. Phosphorylated STAT3 dimerizes and translocates to the nucleus to regulate target gene transcription [27]. In addition, CNTF can also trigger and activate PI3K/Akt or MEK/ERK pathways, either concomitantly or independently of JAK2/STAT3 signalling pathway $[1,5,6,24]$.

In cell-culture experiments, CNTF has also been established to be an important neurocytokine for the survival of a variety of neuronal subpopulations, including dorsal root ganglia, sympathetic neurons, GABAergic septohippocampal neurons, and motor neurons $[8,9]$. A previous study conducted by Kazunori et al. has found that CNTF may promote the survival and neurite outgrowth of DRG neuron from an adult rat after it had been cultured for 7 days [24]. However, currently, there is little information available on the effects of CNTF on human neuroblastoma cells. Human neuroblastoma cells are currently used as an in vitro model of neuronal function and differentiation [20]. In particular, a human neuroblastoma dopaminergic neuronal cell line - SH-SY5Y is used as a model for neurodegenerative disorders as the cells can be converted to various types of functional neurons through the addition of specific compounds such as retinoic acid (RA), phorbol ester or staurosporine $[2,17]$. In many studies, SH-SY5Y neuroblastoma cells are often induced to differentiate by RA to obtain more neuron-like properties, including neurite outgrowth and morphological changes, this in turn allows the mimicking of responses of neurons [7]. A previous study has reported that SH-SY5Y neuroblastoma cells expressed functional CNTF receptors and the expression levels were found to increase several folds through continuous exposure to RA $[10,18]$. However, limited studies have been reported about the CNTF response of SH-SY5Y neuroblastoma cells following RA treatment.

In this study, we tried to elucidate the biological effects of CNTF on RA-predifferentiated SH-SY5Y neuroblastoma cells for the first time. Moreover, the underlying molecular mechanisms of such effects were also explored in regards to change of related signalling pathways in SH-SY5Y neuroblastoma cells.

\section{Material and methods \\ Materials and chemicals}

Recombinant human CNTF was produced in Escherichia coli by our laboratory. The purity of CNTF is higher than $95 \%$ by high-performance liquid chroma- tography (HPLC) and the molecular weight of which is $24 \mathrm{kDa}$ by sodium dodecyl sulfate-polyacrylamide gel electrophoresis SDS-PAGE (data not shown). All cell culture reagents were purchased from Gibco (Grand Island, NY, USA). Retinoic acid, AG490, Curcumin, LY-294002 and PD98059 were purchased from Sigma-Aldrich (St Louis, Mo, USA). Trypan blue, Ribonuclease A (Rnase A), Polyvinylidene Fluoride (PVDF) membranes and enhanced chemiluminescence (ECL) detection kit were purchased from Beyotime (Nantong, China). Antibodies against CNTFR $\alpha$, gp130, LIFR and $\beta$-actin were obtained from Santa Cruz Biotechnology (CA, USA). Antibodies against P-STAT3, STAT3, P-Akt, Akt, P-ERK1/2, ERK1/2 were obtained from Cell Signalling Technology (MA, USA). All other chemicals and reagents were of analytical grade.

\section{Cell culture}

The SH-SY5Y neuroblastoma cell line was obtained from the Shanghai Institute of Cell Biology, Chinese Academy of Sciences (Shanghai, China). Cells were grown in Dulbecco's modified Eagle's medium (DMEM) supplemented with $10 \%$ foetal bovine serum and $1 \%$ penicillin-streptomycin. Cells were maintained at $37^{\circ} \mathrm{C}$ in a saturated humidity atmosphere containing $95 \%$ of air and $5 \%$ of $\mathrm{CO}_{2}$. The medium was changed every 3 days. For cell survival and neurite outgrowth, cells were plated in 35-mm-diameter (Corning, NY, USA) at an initial density of $5 \times 10^{4}$ cells per well.

\section{Assay for cell survival and neurite outgrowth}

The number of living cells was established by staining with trypan blue and counting in the hemocytometer (Bürker). Cells were treated with RA at $10 \mu \mathrm{M}$ for 5 days, washed three times with DMEM and switched to serum-free DMEM medium containing various concentrations of $\operatorname{CNTF}(0,5,50,500 \mathrm{ng} /$ $\mathrm{mL}$ ) for $48 \mathrm{~h}$. Before switching to CNTF-containing medium, the living cells were counted and the resulting value was defined as $100 \%$ survival. Results were therefore expressed as a mean \pm SEM percentage of this value. For evaluation of neurite outgrowth, cells treated with the indicated drugs were observed in a phase-contrast microscope (Olympus X51, Japan) and the cell bodies and neurites were counted. The ratio between neurites and cell bodies was calculated yielding the average of neurites per neuron. 


\section{Measurement of neuropoietic activities of CNTF in the presence of signalling pathway inhibitors}

The effects of related signalling pathway inhibitors on the CNTF-induced survival and neurite outgrowth of RA-differentiated SH-SY5Y neuroblastoma cells were investigated. Cells were treated for 5 days with RA at $10 \mu \mathrm{M}$ and then cultured with CNTF (50 ng/ $\mathrm{mL}$ ) in the absence or presence of JAK2 inhibitor AG490 (25 $\mu \mathrm{M})$, STAT3 inhibitor Curcumin (50 $\mathrm{MM})$, PI3K inhibitor LY-294002 (50 $\mathrm{MM})$ and MEK inhibitor PD98059 (50 $\mu \mathrm{M})$ for $48 \mathrm{~h}$, respectively. The survival and neurite outgrowth of cells were evaluated.

\section{Immunocytochemistry}

Cells were collected and fixed with $4 \%$ paraformaldehyde for $10 \mathrm{~min}$ at $4{ }^{\circ} \mathrm{C}$, and then treated with $0.1 \%$ Triton-X-100 in phosphate buffer saline (PBS) for 5 min at room temperature or with $100 \%$ methanol for $10 \mathrm{~min}$ at $-20^{\circ} \mathrm{C}$. The fixed cells were incubated overnight at $4^{\circ} \mathrm{C}$ with CNTFR antibody, gp130 polyclonal antibody and LIFR antibody, respectively. All of which were diluted with $20 \mathrm{mM}$ of PBS containing $0.4 \%$ Block Ace. After rinsing with PBS, the cells were incubated for $1 \mathrm{~h}$ at $37^{\circ} \mathrm{C}$ with peroxidase-conjugated secondary antibodies. The immunoreaction was visualized as described above.

\section{Western blot analysis}

Cell extracts were prepared from cultured cells using lysis buffer (10 mM of Tris [pH 7.4], $150 \mathrm{mM}$ of $\mathrm{NaCl}, 5 \mathrm{mM}$ of ethylenediaminetetraacetic acid
[EDTA], 1\% Triton-X-100, 1\% Tergitol-type NP40, and the following protease inhibitors: aprotinin, benzamidine, leupeptin, pepstatin A, and phenylmethanesulfonyl fluoride [PMSF]). The protein concentration of samples was determined with Bradford method [25]. The samples $(50 \mu \mathrm{g})$ were then applied to $10 \%$ SDS-PAGE and transblotted onto PVDF membranes. After blocking with $5 \%$ bovine serum albumin (BSA) in Tris-buffer saline (TBST) for 1 hour, membranes were incubated with the primary antibodies (all in 1 : 500 dilutions) overnight and followed by a secondary antibody (all in $1: 200$ dilutions) incubation for 1 hour at room temperature. Protein bands were visualized by ECL detection kit. The density of each band was normalized by $\beta$-actin.

\section{Statistical analysis}

All data are expressed as mean \pm SEM. Point-topoint comparisons were made by Student's $t$-test. Groups were compared by two-way ANOVA using the unpaired Tukey-Kramer method as post-test. All experiments were done in triplicates and the results were indicative of three independent studies. Results were considered significantly different if $P<0.05$.

\section{Results}

\section{Effects of RA treatment on the expressions of CNTF receptors}

The immunocytochemical analysis confirmed that SH-SY5Y neuroblastoma cells expressed the CNTF receptor complex (CNTFR $\alpha$, gp130 and LIFR) at the cell surface, which is consistent with previous studies
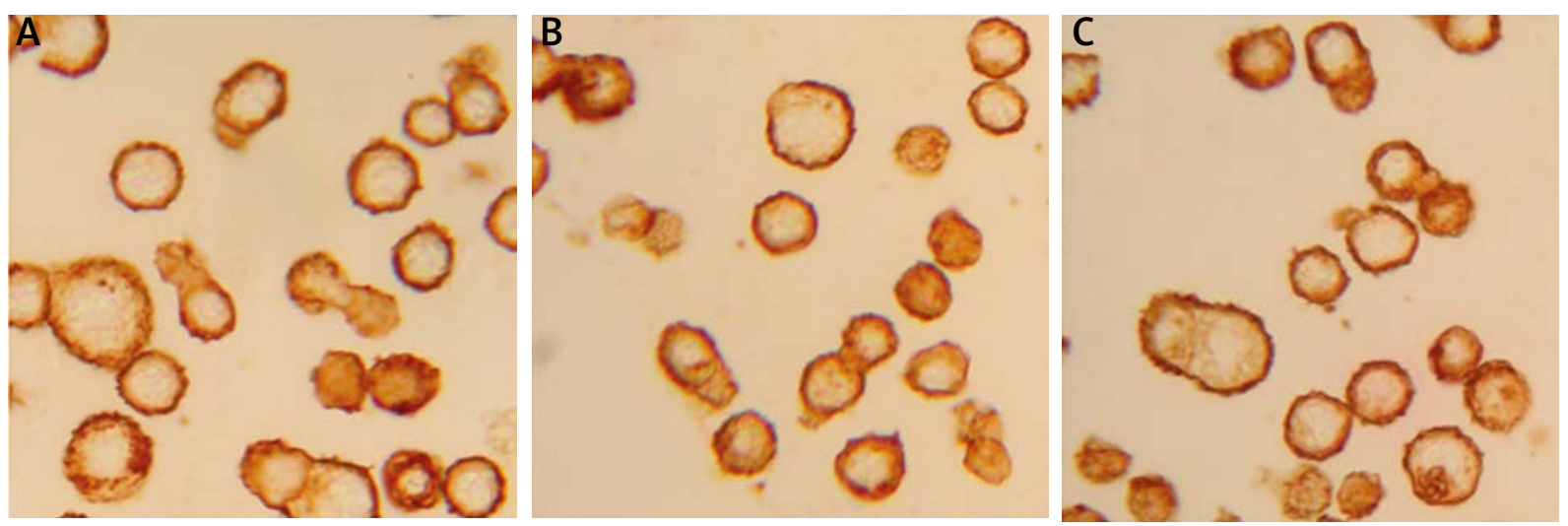

Fig. 1. Immunocytochemical localization of CNTFR $\alpha$, gp130 and LIFR at the surface of cultured SH-SY5Y neuroblastoma cells. Cells were cultured for $24 \mathrm{~h}$ and the peroxidase reactions with antibodies to CNTFR $\alpha$ (A), gp130 (B) and LIFR (C) were performed by immunocytochemical analysis. 
NS
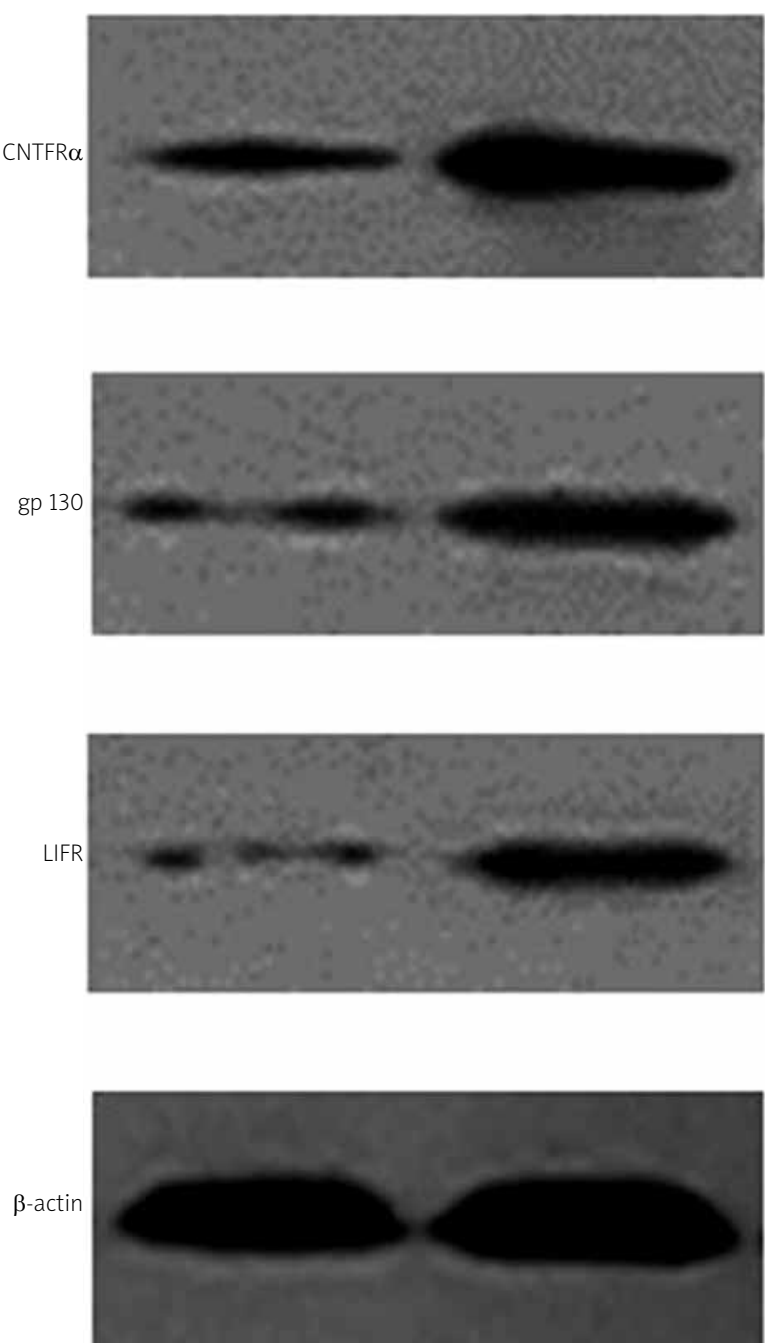

Fig. 2. Effects of RA treatment on the expressions of CNTF receptors (CNTFR $\alpha$, gp130 and LIFR) on cultured SH-SY5Y neuroblastoma cells. Cells were treated for 5 days with $10 \mu \mathrm{M}$ RA and the reactions with antibodies to CNTFR $\alpha$, gp130 and LIFR (all in $1: 500$ dilutions) were performed by western blot analysis. NS: non-stimulated cells.

(Fig. 1) [12,18]. Effects of exposure of RA on the up-regulation of the expression level of CNTF receptors were also examined. As shown in Fig. 2, a 2.2-fold increase for CNTFR $\alpha, 2.7$-fold increase for gp130 and 3.2-fold increase for LIFR in band intensity after 5 days of RA treatment $(10 \mu \mathrm{M})$ as compared to those of non-stimulated controls were observed. The results suggested that RA might increase the responsiveness of CNTF via regulating the levels of CNTF receptors.

\section{Effects of CNTF on survival and neurite growth of RA-pretreated cells}

SH-SY5Y neuroblastoma cells were cultured for 5 days in the presence of $10 \mu \mathrm{M}$ RA and then switched to serum-free medium supplemented with CNTF at various concentrations. After an additional 48 hours in culture, cell survival was evaluated by means of the trypan blue staining. The results showed that CNTF had a significant effect on the cell survival of RA-pretreated cells (Fig. 3A). In addition, effects of CNTF on neurite growth were further investigated. After cultured with CNTF for 48 hours, RA-pretreated cells acquired rounded, phase-bright bodies and displayed long neurites and the ratio between neurites and cell bodies was increased in a dose-dependent relationship (Fig. 3B).

\section{Effects of CNTF on signalling pathways of RA-pretreated cells}

The activation status of CNTF receptors-related signalling pathways was assessed to elucidate the molecular mechanism of the biological effects of CNTF. Western blot analysis showed that cells treated by RA for 5 days were acutely stimulated by CNTF where the expressions of phosphorylated signalling molecules including P-STAT3, P-Akt and P-ERK $1 / 2$ were undetectable initially but were rapidly induced by co-treatment with CNTF for $15 \mathrm{~min}$ and still detectable after $4 \mathrm{~h}$ of exposure to CNTF (Fig. 4). These findings suggested that CNTF could induce phosphorylation of STAT3, Akt and ERK1/2 in RA-pretreated SH-SY5Y cells.

\section{Effects of signalling pathway inhibitors on CNTF-induced survival and neurite growth of RA-pretreated cells}

Based on previous results, we further investigated which pathways are involved in CNTF-induced survival and neurite outgrowth, using the inhibitors of individual pathways: JAK2 inhibitor - AG490, STAT3 inhibitor - Curcumin, PI3K inhibitor - LY-294002 and MEK inhibitor - PD98059. The promoting activity of CNTF on survival and neurite growth of RA-pretreated cells was attenuated by co-treatment with AG490 (25 $\mu \mathrm{M})$, Curcumin (50 $\mu \mathrm{M}), \mathrm{LY} 294002(50 \mu \mathrm{M})$, but not by co-treatment with PD98059 $(50 \mu \mathrm{M})$. These findings suggested that the JAK2/STAT3 pathway, as well as PI3K/Akt pathway, were the principal pathways in CNTF-induced survival and neurite growth of RA-pretreated cells. 

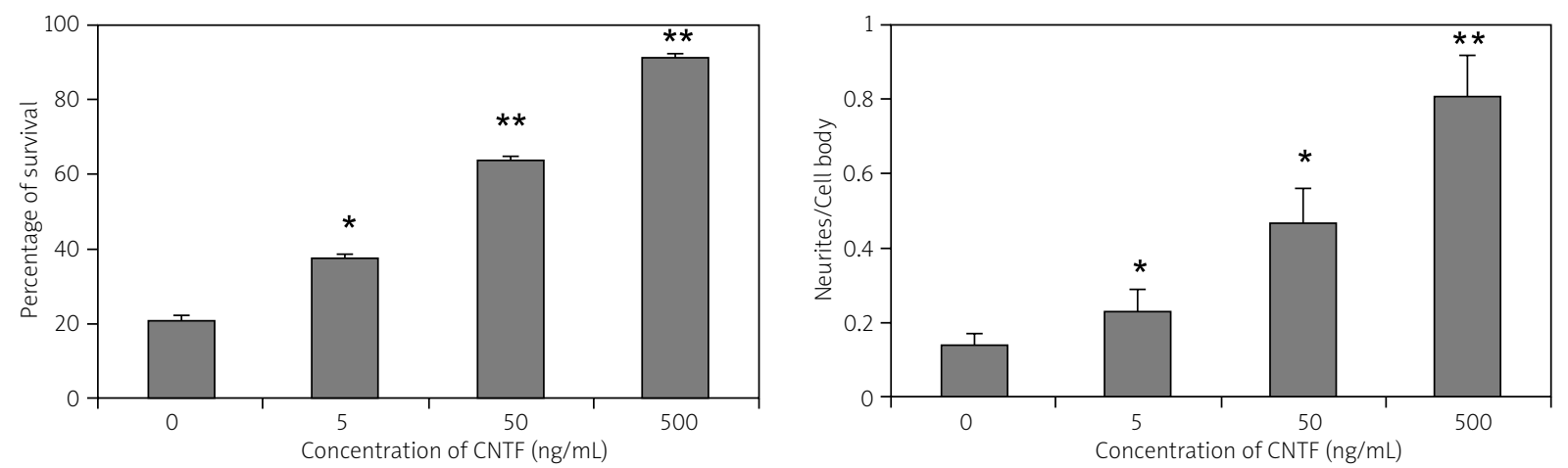

Fig. 3. Effects of CNTF on survival and neurite growth of RA-pretreated SH-SY5Y neuroblastoma cells. Cells were treated for 5 days with $10 \mu \mathrm{M}$ RA and then cultured in a serum-free medium containing the indicated concentrations of $\operatorname{CNTF}(0,5,50,500 \mathrm{ng} / \mathrm{mL})$ for an additional period of $48 \mathrm{~h}$. A) Cell survival was assessed by trypan blue staining. B) Neurite outgrowth of cells was scored as described in Materials and methods. Data are mean \pm SEM values. ${ }^{\star} P<0.05$ vs. control, ${ }^{\star *} P<0.01$ vs. control.

\section{Discussion}

Until now, few studies have focused on the effects of CNTF on human neuroblastoma cells such as SH-SY5Y, which could be differentiated to neuronal-like cells using retinoic acid and used as a model for neurodegenerative disorders [15,22,23]. In this study, we examined the biological effects of CNTF on RA-predifferentiated SH-SY5Y neuroblastoma cells for the first time and further explored the molecular mechanisms of such effects.

Our data confirmed that SH-SY5Y cells express a functional CNTF receptor complex including CNTFR $\alpha$, gp130 and LIFR at the cell surface and showed a stable increase in protein levels after treatment with RA for 5 days, which are consistent with those in previous studies [23]. We further investigated if RA pretreatment was able to enhance the cells sensitivity to CNTF via regulating the CNTF receptor levels. The results showed that CNTF exerted the most striking effects on cell survival and neurite growth of RA-pretreated cells compared with those lacking neurotrophic support, which indicated that high expressions of CNTF receptors induced by RA are biologically active.

The JAK2/STAT3 pathway is the main signalling cascade used by CNTF in many cell types, however, CNTF can also signal through PI3K/Akt and/or MEK/ ERK pathways [13]. To clarify this, the signalling pathway of CNTF in RA-predifferentiated SH-SY5Y neuroblastoma cells was also investigated in this study. The results from our western blot analysis indicated that

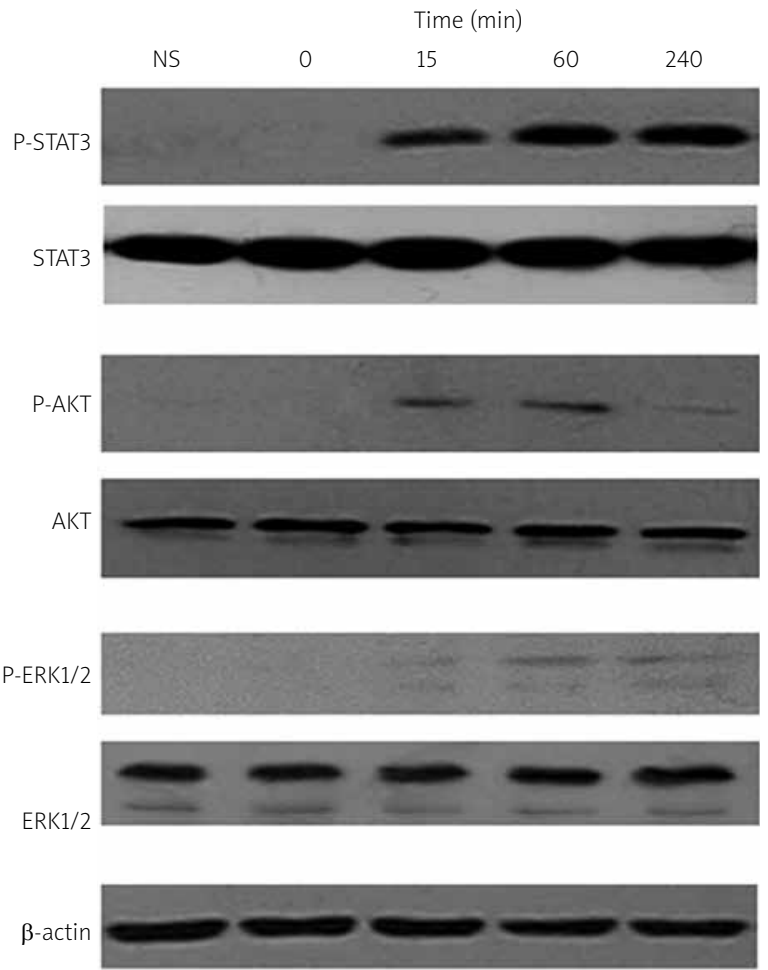

Fig. 4. Effects of CNTF on the expressions of signalling pathway molecules on RA-pretreated SH-SY5Y neuroblastoma cells. Cells were treated for 5 days with $10 \mu \mathrm{M}$ RA and cultured in serum-free medium containing the $50 \mathrm{ng} / \mathrm{mL}$ CNTF for an additional time. Then, the reactions with antibodies to P-STAT3, STAT3, P-Akt, Akt, P-ERK1/2, ERK1/2 (all in $1: 500$ dilution) were performed by western blot analysis. The density of each band was normalized by $\beta$-actin. NS: non-stimulated cells. 

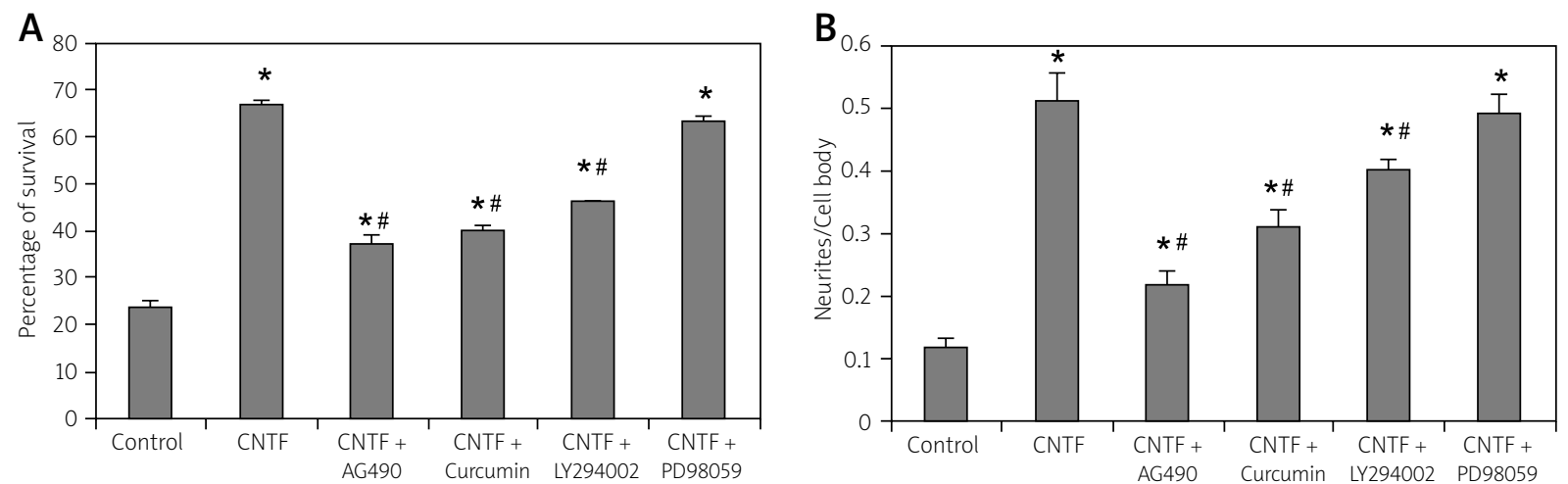

Fig. 5. Effects of signalling pathway inhibitors on CNTF-induced survival and neurite growth of RA-pretreated SH-SY5Y neuroblastoma cells. Cells were treated for 5 days with $10 \mu \mathrm{M}$ RA and then cultured in serumfree medium containing the CNTF $(50 \mathrm{ng} / \mathrm{mL})$ and inhibitors [AG490 $(25 \mu \mathrm{M})$, Curcumin $(50 \mu \mathrm{M})$, LY-294002 $(50 \mu \mathrm{M})$ and PD98059 $(50 \mu \mathrm{M})$ ] for an additional period of $48 \mathrm{~h}$. A) Cell survival was assessed by trypan blue staining. B) Neurite outgrowth of cells was scored as described in Materials and methods. Data are mean \pm SEM values. ${ }^{*} P<0.05$ vs. control, ${ }^{\#} P<0.05$ vs. CNTF.

CNTF could induce the expressions of phosphorylated signalling molecules including P-STAT3, P-Akt and P-ERK $1 / 2$ in cells pretreated by RA. Further survival and neurite outgrowth assays showed that promoting activity of CNTF was attenuated by co-treatment with JAK2 inhibitor AG490, STAT3 inhibitor Curcumin, PI3K inhibitor LY294002, but not by co-treatment with MEK inhibitor PD98059. These findings suggested that the MEK/ERK pathway is unlikely to be a crucial pathway for CNTF-induced survival and neurite outgrowth activity of RA-predifferentiated SH-SY5Y neuroblastoma cells, while the JAK2/STAT3 pathway, as well as PI3K/Akt pathway, played important roles in mediating the neuroprotective function of CNTF. Further research is required to elucidate how these signalling pathways exert their effect during CNTF-induced survival and neurite outgrowth in RA-predifferentiated SH-SY5Y neuroblastoma cells.

In conclusion, our study has enhanced our understanding towards the functional role of CNTF on RA-predifferentiated SH-SY5Y neuroblastoma cells in promoting cell survival and neurite growth. We also found that the JAK2/STAT3 and PI3K/Akt signalling pathways are mainly involved in the CNTF-induced survival and neurite outgrowth activity of RA-predifferentiated SH-SY5Y neuroblastoma cells. These results may supplement the current understanding of how CNTF functions in diverse tissues and organisms, which offers a convenient model to explore the therapeutic potential of CNTF in neurodegenerative diseases.

\section{Acknowledgements}

This work is supported by grants from the National Natural Science Foundation (81300787), the Natural Science Foundation of Jiangsu Province (BK2011168, BK2012105) and the Technology Infrastructure Plan of Jiangsu Province - Technology Public Service Platform (BM2012066).

\section{Disclosure}

Authors report no conflict of interest.

\section{References}

1. Alonzi T, Middleton G, Wyatt S, Buchman V, Betz UA, Müller W, Musiani P, Poli V, Davies AM. Role of STAT3 and PI 3-knase/ Akt in mediating the survival actions of cytokines on sensory neurons. Mol Cell Neurosci 2001; 18: 270-282.

2. Cheung Y-T, Lau WK-W, Yu M-S, Lai CS-W, Yeung S-C, So K-F, Chang RC-C. Effects of all-trans-retinoic acid on human SH-SY5Y neuroblastoma as in vitro model in neurotoxicity research. Neurotoxicology 2009; 30: 127-135.

3. Davis S, Aldrich TH, Stahl N, Pan L, Taga T, Kishimoto T, Ip NY, Yancopoulos GD. LIFR beta and gp130 as heterodimerizing signal transducers of the tripartite CNTF receptor. Science 1993; 260: 1805-1808.

4. Davis S, Aldrich TH, Valenzuela DM, Wong V, Furth ME, Squinto SP, Yancopoulos GD. The receptor for ciliary neurotrophic factor. Science 1991; 253: 59-63.

5. Dolcet X, Soler RM, Gould TW, Egea J, Oppenheim RW, Comella JX. Cytokines promote motoneuron survival through the Janus kinase-dependent activation of the phosphatidylinositol 3-kinase pathway. Mol Cell Neurosci 2001; 18: 619-631. 
6. Do Rhee K, Goureau O, Chen S, Yang X-J. Cytokine-induced activation of signal transducer and activator of transcription in photoreceptor precursors regulates rod differentiation in the developing mouse retina. J Neurosci 2004; 24: 9779-9788.

7. Encinas M, Iglesias M, Liu Y, Wang H, Muhaisen A, Cena V, Gallego C, Comella JX. Sequential Treatment of SH-SY5Y Cells with Retinoic Acid and Brain-Derived Neurotrophic Factor Gives Rise to Fully Differentiated, Neurotrophic Factor-Dependent, Human Neuron-Like Cells. J Neurochem 2000; 75: 991-1003.

8. Ernsberger U, Sendtner M, Rohrer H. Proliferation and differentiation of embryonic chick sympathetic neurons: effects of ciliary neurotrophic factor. Neuron 1989; 2: 1275-1284.

9. Ip N, Li Y, Van de Stadt I, Panayotatos N, Alderson R, Lindsay R. Ciliary neurotrophic factor enhances neuronal survival in embryonic rat hippocampal cultures. J Neurosci 1991; 11: $3124-$ 3134.

10. Johnson RM, McNeeley PA, DeMoor K, Stewart GR, Glaeser BS, Pitchford S. Recombinant human ciliary neurotrophic factor stimulates the metabolic activity of SH-SY5Y cells as measured by a cytosensor microphysiometer. Brain Res 1994; 646: 327-331.

11. Kaur N, Kim IJ, Higgins D, Halvorsen SW. Induction of an interferon- $\gamma$ Stat3 response in nerve cells by pre-treatment with gp130 cytokines. J Neurochem 2003; 87: 437-447.

12. Kaur N, Wohlhueter AL, Halvorsen SW. Activation and inactivation of signal transducers and activators of transcription by ciliary neurotrophic factor in neuroblastoma cells. Cell Signal 2002; 14: 419-429.

13. Kruger NJ. The Bradford method for protein quantitation. In: Basic Protein and Peptide Protocols. Walker JM (ed). Humana Press, New York 1994; pp. 9-15.

14. Linker R, Gold R, Luhder F. Function of neurotrophic factors beyond the nervous system: inflammation and autoimmune demyelination. Crit Rev Immunol 2009; 29: 43-68.

15. Li P, Wang Z, Yan J, Li Z, Jiang C, Ni X, Yang Y, Liu F, Lu C. Neuro-protective effects of CNTF on hippocampal neurons via an unknown signal transduction pathway. Chin Sci Bull 2006; 51: 48-53.

16. Maisonpierre PC, Belluscio L, Squinto S, Ip NY, Furth ME, Lindsay RM, Yancopoulos GD. Neurotrophin-3: a neurotrophic factor related to NGF and BDNF. Science 1990; 247: 1446-1451.

17. Malek RL, Halvorsen SW. ciliary neurotrophic factor and phorbol ester each decrease selected STAT3 pools in neuroblastoma cells by proteasome-dependent mechanisms. Cytokine 1999; 11: 192-199.

18. Malek RL, Halvorsen SW. Opposing regulation of ciliary neurotrophic factor receptors on neuroblastoma cells by distinct differentiating agents. J Neurobiol 1997; 32: 81-94.

19. Negro A, Corona G, Bigon E, Martini I, Grandi C, Skaper S, Callegaro L. Synthesis, purification, and characterization of human ciliary neuronotrophic factor from E. coli. J Neurosci Res 1991; 29: 251-260.

20. Påhlman S, Mamaeva S, Meyerson G, Mattsson ME, Bjelfman C, Ortoft E, Hammerling U. Human neuroblastoma cells in culture: a model for neuronal cell differentiation and function. Acta Physiol Scand Suppl 1990; 592: 25-37.

21. Recio-Pinto E, Rechler MM, Ishii D. Effects of insulin, insulin-like growth factor-II, and nerve growth factor on neurite formation and survival in cultured sympathetic and sensory neurons. J Neurosci 1986; 6: 1211-1219.

22. Rezende LF, Stoppiglia LF, Souza KL, Negro A, Langone F, Boschero AC. Ciliary neurotrophic factor promotes survival of neonatal rat islets via the $\mathrm{BCL}-2$ anti-apoptotic pathway. J Endocrinol 2007; 195: 157-165.

23. Saleh A, Roy Chowdhury SK, Smith DR, Balakrishnan S, Tessler L, Martens C, Morrow D, Schartner E, Frizzi KE, Calcutt NA. Ciliary neurotrophic factor activates NF- $\kappa \mathrm{B}$ to enhance mitochondrial bioenergetics and prevent neuropathy in sensory neurons of streptozotocin-induced diabetic rodents. Neuropharmacology 2012; 65: 65-73.

24. Sango K, Yanagisawa H, Komuta Y, Si Y, Kawano H. Neuroprotective properties of ciliary neurotrophic factor for cultured adult rat dorsal root ganglion neurons. Histochem Cell Biol 2008; 130: 669-679.

25. Stahl N, Yancopoulos GD. The tripartite CNTF receptor complex: activation and signaling involves components shared with other cytokines. J Neurosci 1994; 25: 1454-1466.

26. Wishingrad MA, Koshlukova S, Halvorsen SW. Ciliary neurotrophic factor stimulates the phosphorylation of two forms of STAT3 in chick ciliary ganglion neurons. J Biol Chem 1997; 272: 19752-19757.

27. Zhong Z, Wen Z, Darnell J. Stat3: a STAT family member activated by tyrosine phosphorylation in response to epidermal growth factor and interleukin-6. Science 1994; 264: 95-98. 